\section{Estudo \\ Ecibate}

em Testão

Plamejamento
Revista Estudo \& Debate, Lajeado, v. 25, n. 1, 2018. ISSN 1983-036X

DOI: http://dx.doi.org/10.22410/issn.1983-036X.v25ila2018.1490

\title{
DESEMPENHO DA PROVISÁO DOS SERVIÇOS DE SANEAMENTO BÁSICO NO CEARÁ
}

\author{
Erivelton de Souza Nunes ${ }^{1}$, Francisco Diego Guedes Ferreira ${ }^{2}$, Eliane Pinheiro de Sousa ${ }^{3}$
}

\begin{abstract}
Resumo: Em face da relevância do saneamento básico para a saúde pública e o meio ambiente, este estudo se propóe a mensurar um Índice de Desempenho da provisão dos serviços de Saneamento Básico (IDSB) no estado do Ceará e comparar o IDSB dos municípios cearenses antes e após a vigência da Lei Nacional de Saneamento Básico (LNSB). Essa lei visa o delineamento de novas políticas setoriais para a ampliação do acesso universal à água e do saneamento básico, via incremento de investimentos. Para atender a tais objetivos, empregouse o método multivariado de análise fatorial. Os dados utilizados foram provenientes do Sistema Nacional de Informaçóes sobre Saneamento (SNIS) e referem-se aos anos de 2006 e 2015. Os resultados mostraram que, apesar da predominância do IDSB intermediário nos dois períodos considerados, parcela majoritária dos municípios cearenses registrou uma melhoria no desempenho da provisáo dos serviços de saneamento básico após a implementação da Lei Nacional de Saneamento Básico, uma vez que cerca de 39\% dos municípios analisados passaram do nível baixo para intermediário.
\end{abstract}

Palavras-chave: saneamento básico, análise fatorial, Lei Nacional de Saneamento Básico.

\section{PERFORMANCE OF THE PROVISION OF BASIC SANITATION SERVICES IN CEARÁ}

Abstract: In view of the relevance of basic sanitation to public health and the environment, this study is aimed at measuring an index of performance of the provision of basic sanitation services (IDSB, acronym in Portuguese) in the state of Ceará and at comparing the IDSB of the municipalities of the state of Ceará before and after the coming into force of the National Basic Sanitation Act (LNSB). This act is aimed at outlining new

1 Graduado em Ciências Econômicas pela Universidade Regional do Cariri (URCA), Mestrando em Economia Rural pela Universidade Federal do Ceará (UFC), Bolsista pelo Conselho Nacional De Desenvolvimento Científico e Tecnológico (CNPq);

2 Graduando em Ciências Econômicas pela Universidade Regional do Cariri (URCA), Bolsista de Iniciação Cientifica pelo Conselho Nacional De Desenvolvimento Científico e Tecnológico (CNPq);

3 Graduada em Ciências Econômicas pela Universidade Federal do Ceará, Mestre em Economia Rural pela Universidade Federal do Ceará, Doutora em Economia Aplicada pela Universidade Federal de Viçosa, PósDoutora em Economia Aplicada pela Escola Superior de Agricultura Luiz de Queiroz da Universidade de São Paulo, Professora Associada do Departamento de Economia da Universidade Regional do Cariri (URCA). 
sectorial policies for the expansion of the universal access to water and basic sanitation, through the increase of investments. In order to meet such objectives, it was used the multivariate method of factor analysis. The data used were extracted from the National Information System on Sanitation (SNIS) and relate to the years 2006 and 2015. The results showed that, in spite of the predominance of the intermediate IDSB in the two periods under analysis, the majority of the municipalities of the state of Ceará exhibited an improvement in the performance of the provision of basic sanitation services after the implementation of the National Basic Sanitation Act, as around 39\% of the municipalities that were analyzed passed from the low to the intermediate level.

Keywords: basic sanitation, factor analysis, National Basic Sanitation Act.

\section{INTRODUÇÁO}

No Brasil, o déficit do setor de saneamento básico é elevado, em especial, o esgotamento sanitário, sendo que as áreas periféricas dos centros urbanos e os meios rurais apresentam maior carência (GALVÃO JÚNIOR, PAGANINI, 2009).

O Nordeste do Brasil destaca-se como deficitário em termos de infraestrutura de água e esgoto (GALVÃO JÚNIOR, 2008). Este autor ainda enfatiza, com base no IBGE (2001), que dos 45 milhóes de domicílios brasileiros, 35 milhóes estavam conectados à rede de distribuição de água, 7 milhôes possuíam poço ou nascente e 3 milhôes, outras fontes de abastecimento de água. Desse total atendido por outras fontes, como reservatório abastecido por carro-pipa ou água de chuva, $67 \%$ localizavam no Nordeste. Em relação ao esgotamento sanitário, 41,1 milhões tinham banheiro ou sanitário, ao passo que 3,7 milhóes eram desprovidos desta infraestrutura, sendo que $72,5 \%$ desses domicílios encontravam-se no Nordeste.

Em conformidade com Venson et al. (2015), um dos objetivos da política pública é reduzir a desigualdade no acesso aos serviços de saneamento básico no Brasil. Para superar esse desafio, esses autores ressaltam que, conforme o Instituto de Pesquisa e Economia Aplicada (IPEA, 2010), é imprescindível expandir o acesso da população que se localiza, sobretudo, em municípios de baixo desenvolvimento humano e pequeno porte, ou em periferias e áreas de urbanizaçáo informal e precária.

Dados divulgados no Diário do Nordeste (2011) revelam que embora o estado do Ceará tenha avançado em diversos aspectos da condição de moradia das famílias extremamente pobres em relação à média brasileira, registrou péssimo desempenho em outros pontos relevantes. Dentre esses, o pior desempenho refere-se ao serviço de abastecimento de água tratada e tratamento de esgoto, ficando o Estado muito abaixo náo apenas em termos comparativos com os parâmetros nacionais, mas quanto ao Nordeste.

Nesse contexto, estudos que discutam essa temática no Ceará são importantes no sentido de identificar as deficiências e sinalizar estratégias que minimizem os problemas enfrentados. O estudo desenvolvido por Silva (2009) analisou os determinantes individuais e domiciliares da demanda pelo serviço de saneamento básico no Ceará.

Segundo Galvão Júnior e Paganini (2009), existem vários fatores responsáveis pelo déficit de água e esgoto no país, sendo que um deles se refere à fragmentação de políticas públicas e a carência de instrumentos de regulação. $\mathrm{Na}$ concepção desses autores, apesar dos esforços do governo federal para criar, a partir de 2003, o Ministério das Cidades e a 
Secretaria Nacional de Saneamento, desde o final dos anos 1980, com a extinção do Plano Nacional de Saneamento, o país não dispóe de política setorial consistente (PLANASA).

Apenas no princípio de 2007, foi promulgada a lei n. 11.445/2007, que estabelece as diretrizes nacionais para o saneamento básico, definindo instrumentos e regras para o planejamento, fiscalização, prestação e a regulação dos serviços, com o controle social sobre todas essas funçôes. Além da transparência, tecnicidade, celeridade e objetividade das decisões, essa regulação deve ser realizada com independência, determinada como autonomia administrativa, orçamentária e financeira da entidade reguladora (GALVÃO JÚNIOR, PAGANINI, 2009).

Desde a aprovação dessa nova Lei Nacional de Saneamento Básico (LNSB), em 2007, os serviços de saneamento básico, que englobam tanto o caráter de cadeia industrial para fins de provisão de bens públicos como a rede de serviços públicos destinados à efetivaçáo de direitos sociais, vêm passando por um substancial processo de transformação institucional (CUNHA, 2011). Para esse autor, a edição de uma nova moldura institucional desempenha papel relevante para os serviços de saneamento básico.

Em face do exposto, reveste-se de importância investigar se a LNSB contribuiu para uma melhoria no desempenho da provisão dos serviços de saneamento básico no estado do Ceará. Para isso, foi realizada uma análise antes e após a implementação dessa lei. Estudos que buscam avaliar os efeitos de leis de saneamento foram objetos de estudo de Cardoso et al. (2015), Venson et al. (2015) e Diniz (2016), respectivamente, da Lei Estadual n. 7.358/2000 sobre a situaçáo do saneamento sem a companhia estadual em Mato Grosso por meio do estabelecimento da técnica de controle sintético e da Lei n. 11.445/2007 nas microrregióes brasileiras, utilizando o método de análise exploratória de dados espaciais e sobre os serviços brasileiros de abastecimento de água e esgotamento sanitário, empregando os métodos de Análise Envoltória de Dado (DEA) e do Índice de Malmquist.

Portanto, o principal objetivo deste estudo consiste em avaliar o desempenho da provisão dos serviços de saneamento básico no Ceará. Especificamente, propóe-se mensurar um índice de desempenho da provisão dos serviços de saneamento básico no Ceará, considerando indicadores operacionais; de produtividade, econômicos e administrativos; e de investimento, e comparar o desempenho da provisão dos serviços de saneamento básico no estado do Ceará antes e após a implementação da Lei Nacional de Saneamento Básico (LNSB), instituída em 2007.

\section{REVISÃO BIBLIOGRÁFICA}

\subsection{Saneamento básico: fundamentos teóricos e evidências empíricas}

O saneamento básico abrange o abastecimento de água, recolhimento e tratamento de esgotamento sanitário, limpeza urbana com o manejo dos resíduos sólidos e a drenagem das águas pluviais urbanas (CARDOSO; MELO; DALFAVO, 2015). A relevância desse serviço público é defendida na literatura internacional e nacional.

No contexto internacional, Kemper e Sadoff (2003) destacam que o acesso à água potável e ao saneamento básico é imprescindível para a saúde pública e necessário para a 
sustentação da vida humana. A ampliação do abastecimento de água e as melhores condições de saneamento, bem como a eficiência no gerenciamento dos recursos hídricos são capazes de contribuir para o crescimento econômico dos países e gerarem reflexos positivos sobre a redução da pobreza.

Para Caruso et al. (2014), melhorias no saneamento básico podem beneficiar a educação de alunos de escolas primárias nos países subdesenvolvidos, uma vez que o acesso a água limpa e boas condiçóes de saneamento podem prover maior assiduidade e aprendizagem nas escolas. Anthonj et al. (2016) e Ortiz-Correa, Resende Filho e Dinar (2016) complementam que a desigualdade no acesso à água e ao saneamento gera efeitos negativos sobre a saúde e a educação, haja vista que os partícipes de uma dada família, especialmente as crianças, apresentam maior tendência de contágio de doenças associadas à água. Assim, a ausência de serviços adequados de água e saneamento e a falta de higienização adequada intensificam a probabilidade de transmissáo de doenças.

A melhoria do saneamento básico também gera benefícios sociais e econômicos que contemplam custos mais reduzidos do sistema de saúde e maior assiduidade no trabalho, dada o tempo náo gasto com problemas relacionados à ausência de saneamento (HUTTON; HALLER, 2004).

Apesar de toda essa relevância, Rosemarin et al. (2008) afirmam que raramente priorizara-se o setor de saneamento, sendo que muitas vezes o setor sequer integra-se a planejamentos nacionais de desenvolvimento nos diversos países. Segundo a WHO; UNICEF (2017), ao menos $40 \%$ da população mundial sofre com a escassez de água e cerca de 2,4 bilhóes de pessoas não têm acesso a um saneamento básico adequado.

No Brasil, Scriptore e Toneto Júnior (2012) ressaltam a relação direta entre o sistema de saneamento básico e seus impactos na saúde pública. Partindo-se desse pressuposto, evidencia-se que investir em saneamento básico pode refletir em melhoria da qualidade de vida da população. Segundo o IPECE (2011), os domicílios particulares permanentes com abastecimento de água adequada, em 2010, representavam 82,85\%, já em relação ao percentual de municípios com sistema de banheiro ou sanitário ligados à rede geral de esgotos para o mesmo ano, o valor ainda é mais baixo, ficando em torno de 55,45\%.

Nascimento (2011), baseado nos dados do Programa Nacional do Saneamento Básico de 2008, apresenta que 5.256 municípios brasileiros possuem algum serviço de manejo das águas pluviais, correspondendo a 94,5\% dos municípios totais do país. Já para manejo dos resíduos sólidos, Vilanova Neta (2011), apresenta que apenas dois municípios brasileiros não registram nenhum manejo dos seus resíduos sólidos, por outro lado, 50,8\% dos municípios destinam seus resíduos em vazadouros a céu aberto, também conhecido como lixóes, o que se apresenta como um problema, já que nestes, além do não tratamento adequado dos resíduos, ainda existe a problemática social, pois é nos lixóes que uma parcela da população busca sua fonte de renda e até sua própria alimentação.

Para Scriptore e Toneto Júnior (2012, p. 2), “a principal explicação para esse cenário está no descompasso existente entre o nível de investimentos efetivamente realizado e o montante necessário para eliminar o déficit de acesso". Segundo estes autores, atualmente o baixo nível de investimento no setor está relacionado às dificuldades de geração de 
recursos por meio das empresas públicas, seja pela cobrança do serviço aos usuários ou por problemas operacionais ou endividamento. Posto isto, a universalidade do serviço de saneamento básico brasileiro fica na dependência da ampliação de investimentos públicos não vinculados à utilização do serviço, ou a iniciativa privada para gerir o setor.

Segundo Cardoso, Melo e Delfavo (2015), o processo de crescimento do setor de saneamento básico no Brasil se deu de forma paulatina, por meio da implementaçáo de políticas públicas a partir de 1971, com a criação do Plano Nacional de Água e Saneamento - PLANASA. Estes autores afirmam que o PLANASA foi criado com a finalidade de expandir a oferta de água e esgotamento sanitário em todo o território nacional. Para isso, o plano consistia em uma gestáo pública destinada aos estados com cobrança de tarifas visando assim o auto sustento das empresas ligadas ao serviço.

Moreira (1996) ressalta que o PLANASA foi fundamental para o surgimento das companhias estaduais de saneamento básico (Cesb’s), que foram responsáveis pela execução dos objetivos do programa. A criaçáo das Cesb's contribuiu para que os municípios brasileiros, que não possuíam acesso próprio ao abastecimento de água e ao esgotamento sanitário, passassem a ser atendidos pelos serviços das companhias estaduais criadas. As metas do programa foram bem sucedidas no que se refere à ampliação do serviço no país, porém, mesmo com os ganhos obtidos após sua implementação, a problemática do esgotamento sanitário quanto ao tratamento e manejo ainda persistiram. De acordo com Cunha (2011, p. 7), o PLANASA se extinguiu na década de 1990 após a "[...] extinção do Banco Nacional de Habitação (BNH), em 1986, e do Ministério do Interior (Minter), em 1990, a prerrogativa de regular esses serviços públicos não foi redistribuída a nenhuma outra agência estatal, tornando o Planasa acéfalo".

Em 1997, surge como forma de licenciamento ambiental a resolução 237 do Conselho Nacional do Meio Ambiente (CONAMA), com a finalidade da preservação dos recursos hídricos. A esse respeito, Cardoso, Melo e Delfavo (2015, p. 2) declaram que:

\footnotetext{
A Resolução do CONAMA instituía que as concessionárias estaduais de saneamento, por serem usuárias de um recurso natural, estariam sujeitas ao licenciamento ambiental. Isso implicava entáo na necessidade de aplicaçáo de modelos de gestão ambiental, focados na preservação e qualidade ambiental dos recursos hídricos do país.
}

No mesmo ano, foi aprovada a lei federal de número 9.433/97, a nomeada Lei das Águas, de suma importância para o melhor uso dos recursos hídricos no país, já que esta instituiu a Política Nacional dos Recursos Hídricos (PNRH), bem como a criação do Sistema Nacional de Gerenciamento dos Recursos Hídricos (SINGREH), (NAVARES; JACOBI, 2002). Neste sentido, Cardoso, Melo e Delfavo (2015) destacam que esta lei surgiu em um período de escassez hídrica, e que seus princípios estão no "bom uso" dos recursos hídricos e na gestáo destes, para garantir sua disponibilidade e qualidade para as geraçôes presentes e futuras. Entretanto, apenas em 2000, com a criação da Agência Nacional de Águas (ANA), os estados e municípios passaram a cumprir as diretrizes do PNRH.

Embora haja um aparato de antecedentes, a universalização do sistema não foi possibilitada pelos mesmos. Em 2007, foi promulgada a Lei 11.445, também chamada de Lei Nacional do Saneamento Básico. Cardoso, Melo e Delfavo $(2015$, p. 3) afirmam que o 
“[...] objetivo seria o delineamento de novas políticas setoriais para a ampliação ao acesso universal de água e saneamento básico, via incremento de investimentos. Configurando-se no novo marco regulatório do setor [...]". Essa Lei exige que haja a elaboraçáo de planos de gestão dos recursos hídricos em níveis federal, estaduais e municipais, o que visa facilitar a universalização do serviço a partir deste regramento advindo do decreto presidencial de número 7.217/2010, que regulamenta a Lei do Saneamento Básico, tomando como base o exercício financeiro do ano de 2014 como condição para o acesso dos recursos do orçamento da União para investimento neste setor (CARDOSO; MELO; DELFAVO, 2015).

De acordo com os termos da nova lei, os planos para o saneamento básico devem englobar a situação do setor, seus impactos para a qualidade de vida da sociedade, apresentar as metas de curto, médio e longo prazo, bem como programas, açóes e projetos que serão utilizados para atingir os objetivos projetados, além das açóes que possivelmente possam ser utilizadas em casos de emergência (CUNHA, 2011).

Quanto à competência do prestador de serviços, cabe ao titular deste (que pode ser privado ou público agindo de forma direta ou indireta), a elaboração dos planos, a fiscalização do setor, a garantia de qualidade na prestação do serviço e o controle social sobre o mesmo (CUNHA, 2011).

No tocante ao estado do Ceará, objeto desse estudo, segundo o SNIS (2017), o Estado dispóe de quatro grupos de prestadores de serviços de saneamento básico referente ao abastecimento de água e esgotamento sanitário: Companhia de Água e Esgoto do Ceará (CAGECE), Serviço Autônomo de Água e Esgoto (SAAE), Administração Pública Direta e a Sociedade Anônima de Água e Esgoto do Crato (SAAEC).

A CAGECE é o principal prestador dos serviços no estado, onde a mesma atua em 151 municípios, com sistema de abastecimento de água. $\mathrm{O}$ índice de cobertura de abastecimento de água da CAGECE no estado é de 98,16\%. Já o seu sistema de esgotamento sanitário atende 73 cidades, o que corresponde a um índice de cobertura do sistema de esgotamento sanitário de 40,11\% (CAGECE, 2017). Embora estes dados quanto ao abastecimento de água estejam próximos da universalização do sistema, por outro lado, o índice de saneamento básico está longe de ser satisfatório.

O Instituto Trata Brasil (2016) produziu um ranking para analisar o desempenho do saneamento básico nas 100 maiores cidades do país, em 2016. Estes resultados indicaram que o Ceará apresenta uma situação ainda mais crítica que a expressa pela CAGECE. Segundo esse Instituto, o Estado ficou ranqueado entre os dez piores sistemas de saneamento básico do Brasil, em que as três cidades cearenses abordadas no estudo (Fortaleza, Caucaia e Juazeiro do Norte) apresentaram resultados muito insatisfatórios. A capital cearense, Fortaleza, enquadra-se na $69^{a}$ colocação do ranking geral, mas encontra-se entre as dez piores cidades no quesito perdas de distribuição. Já a cidade de Caucaia está classificada em $71^{\text {a }}$ colocada, porém aparece entre as dez piores cidades com relação à água tratada, em que apenas $67,58 \%$ da população são beneficiadas com este serviço. Na pior colocação entre as cidades cearenses e entre as dez piores colocadas do Brasil, está Juazeiro do Norte, classificada em $95^{\mathrm{a}}$ no ranking geral, com uma situação crítica na coleta de esgotos, onde o município possui apenas $21,1 \%$ de cobertura do serviço para a população, enquanto que na 
relação entre investimentos e arrecadação, encontra-se com registro obtido de investimento de apenas 4,3\% de todo o valor arrecadado.

Dada a importância do saneamento básico para a saúde pública e o meio ambiente, a literatura tem se dedicado a mensurar o saneamento como forma de indicar aos governantes públicos a situação atual do setor, seja relacionada à provisão do serviço ou propriamente uma análise da qualidade dos seus provedores. Essa questão é discutida na próxima seção.

\subsection{Mensuraçáo dos indicadores do saneamento básico}

Um indicador é uma medida quantitativa ou qualitativa, utilizada para obter informações relevantes do objeto estudado, sendo este um recurso metodológico capaz de captar a evolução dos aspectos observáveis da análise (FERREIRA; CASSIOLATO; GONZALEZ, 2009).

Posto isto, a mensuração de indicadores é essencial para os estudos científicos, visto que a observação da evolução dos eventos possibilita uma análise temporal do desenvolvimento da realidade. Segundo Fracarolli (2015, p. 19):

[...] é grande a necessidade de que sejam utilizados indicadores adequados, capazes de traduzir a realidade com o mínimo de imperfeição, e mensuração de resultados apropriada, de forma a serem capazes de alertar para os rumos incorretos e incertos de cada política pública, de acordo com a leitura adequada destes índices.

No caso do saneamento básico, os indicadores devem nortear a pesquisa para a qualidade da prestação do serviço. Sendo assim, é relevante que os mesmos levem em consideração as dimensôes ambientais, sociais, infraestruturais, operacionais, regulatórias, dentre outras, a fim de apresentar o desempenho do serviço na área estudada, seja em um dado período ou para avaliar o seu desenvolvimento ao longo do tempo (SCRIPTORE; TONETO JÚNIOR, 2012; CARVALHO; LIMA; SOUSA, 2013; PEREIRA et al., 2015).

A utilização destes indicadores é imprescindível para facilitar a análise e diagnosticar os possíveis problemas, além de formular parâmetros comparativos entre prestadores de serviços e localidades. Dentro de um contexto amplo, os indicadores podem servir para a elaboração de índices de desempenho da prestação do serviço de saneamento básico (SCRIPTORE; TONETO JÚNIOR, 2012; CARVALHO; LIMA; SOUSA, 2013; PEREIRA et al., 2015). Nesse âmbito, Schwemlein, Cronk e Bartram (2016) destacam que o monitoramento da água, saneamento e higiene é fundamental para acompanhar o progresso, melhorar a prestação de contas e demonstrar os impactos dos esforços para melhorar as condiçóes e os serviços, especialmente em países de baixa e média renda. Com esse fim, mediante a revisão bibliográfica, identificaram seis etapas metodológicas para selecionar indicadores que mensurem a água, saneamento e higiene, a saber: definição do objetivo e do escopo; seleção de uma estrutura conceitual; busca de indicadores candidatos; determinação de critérios de seleção; estabelecimento dos critérios; e seleção final dos indicadores.

$\mathrm{Na}$ literatura econômica, os estudos que tratam sobre o saneamento básico baseiamse nos indicadores para qualificar e quantificar os serviços de uma dada área. De acordo com Garfi e Ferrer-Martí (2011), os projetos de água e saneamento para resolver as necessidades de 
pequenas comunidades em países em desenvolvimento são complexos e envolvem tomadas de decisão, que devem considerar os indicadores técnico, socioeconômico e ambiental. Para isso, empregaram a análise multicritério.

Scriptore e Toneto Júnior (2012) utilizaram os indicadores de qualidade, investimento, produtividade (econômica e administrativa) e operacional para fazer uma análise comparativa do desempenho dos provedores públicos e privados no Brasil, a partir do método dos Mínimos Quadrados Ordinários (MQO). Os resultados apontaram que não há evidências de que um grupo seja superior ao outro para os indicadores analisados.

Carvalho, Lima e Sousa (2013) adotaram indicadores relativos à política, fundo e plano municipal do saneamento básico; órgão gestor; instrumentos de fiscalização e regulação; cobrança pela prestação dos serviços; controle social e conselho municipal de saneamento; fiscalizaçáo e legislação; e coleta seletiva do lixo para a construçáo do Índice de Gestão Municipal de Saneamento Básico (IGMSB) a fim de classificar os municípios cearenses segundo o nível de gestáo do saneamento básico. A avaliação desse índice possibilitou a identificação das deficiências da gestão municipal do saneamento básico, que estâo relacionadas ao percentual de conselhos de saneamento básico e a inexistência de planos e fundos municipais de saneamento básico.

Pereira et al. (2015) objetivaram elaborar um Indicador de Qualidade do Saneamento Básico Urbano (IQSBU), e aplicá-lo às cidades paranaenses com mais de 100.000 habitantes, nos anos de 2000 a 2008. Para tal, utilizaram quatro "subindicadores" nomeados como: indicador de qualidade de abastecimento de água, indicador de qualidade de esgotamento sanitário, indicador de qualidade de coleta e disposiçáo de resíduos sólidos e indicador de qualidade de drenagem de águas pluviais. $\mathrm{O}$ método utilizado para formulação do IQSBU consiste em uma média aritmética simples destes subindicadores. Os resultados deste estudo apontaram para uma falta de informaçôes sobre o saneamento básico urbano, principalmente no tocante à drenagem e resíduos sólidos. Já em relação ao desempenho das cidades, foi constatado que, em geral, as cidades paranaenses analisadas apresentaram qualidade no saneamento básico ao menos em um ano analisado, embora nenhuma delas tenha atingido ótima qualidade nos serviços referentes ao saneamento básico.

Diniz (2016) utilizou os indicadores presentes no SNIS, que expressam o uso dos recursos, a abrangência dos serviços e a situação financeira dos prestadores de serviço de saneamento básico, para fazer uma avaliaçấo dos serviços brasileiros de abastecimento de água e esgotamento sanitário nos anos de 2002, 2007 e 2012. Para isso, empregou os métodos de Análise Envoltória de Dado (DEA) e do Índice de Malmquist. Os resultados indicaram que houve melhoria na produtividade em todos os períodos analisados, embora o avanço tenha sido menor no período posterior à LNSB com relaçáo ao período anterior analisado.

Baseando-se nos indicadores utilizados por Scriptore e Toneto Júnior (2012), este estudo em questão tem como foco a criação de um índice de desempenho da provisão dos serviços de saneamento básico no Ceará, com o intuito de viabilizar uma análise comparativa deste índice antes e depois da LNSB, para observar se houve ou não melhoria no desempenho dos serviços no estado. Para isso, o mesmo utiliza o método multivariado de análise fatorial, diferenciando-se assim dos instrumentais analíticos apontados pela 
literatura que trata a respeito dessa questão discutida neste tópico. Desta forma, este método será descrito na seção seguinte.

\section{PROCEDIMENTOS METODOLÓGICOS}

\subsection{Método analítico e área de estudo}

O desempenho da provisão dos serviços de saneamento básico no Ceará foi avaliado mediante o método de análise fatorial, que, conforme Fávero et al. (2009), trata-se de uma técnica multivariada que procura identificar um grupo relativamente pequeno de fatores comuns não correlacionados entre si, que podem ser utilizados para expressar relaçóes entre um vasto número de variáveis correlacionadas. Segundo Hair Jr. et al. (2005) e Mingoti (2005), eleva o poder de explicação da totalidade das variáveis, a partir da condensação de informaçóes importantes no fator, dada uma mínima perda de informaçóes. Tal técnica, portanto, contribui na diminuição da complexidade na interpretação dos dados, possibilitando um maior aproveitamento dos mesmos.

O desenvolvimento do método de análise fatorial necessita de uma série de etapas, quais sejam: análise da matriz de correlaçóes e adequabilidade do método; extração dos fatores iniciais e determinação do total de fatores; rotação e interpretação dos fatores. A primeira etapa trata-se da avaliação da matriz de correlaçóes e verificação da presença de valores significativos como justificativa à utilização da técnica. Um indicativo de adequabilidade do emprego dessa técnica ocorre quando as correlaçóes existentes entre todas as variáveis são reduzidas e as variáveis contidas no mesmo fator apresentam elevada correlação (FÁVERO et al., 2009).

Segundo Fávero et al. (2009), o passo seguinte consiste na utilização do método de extração de fatores, em que se emprega a análise dos componentes principais, haja vista que se considera a variância de todos os dados. Ademais, é necessário que se realize a escolha do número de fatores por meio do critério de raiz latente, cujo número de fatores é escolhido, tendo em vista o número de valores próprios que excedem à unidade. Após a rotação ortogonal da estrutura fatorial original, são mensurados os escores fatoriais para cada elemento amostral, os quais são empregados na elaboração do Índice de Desempenho da provisão dos serviços de Saneamento Básico.

De acordo com Mingoti (2005), tal modelo, formulado por meio da matriz de correlação, realiza o relacionamento das variáveis padronizadas e fatores comuns, sendo possível apresentá-lo a partir das seguintes expressóes:

$$
\begin{aligned}
& Z_{1}=I_{11} F_{11}+I_{12} F+\ldots+I_{1 m} F_{m}+\varepsilon_{1} \\
& Z_{2}=I_{21} F_{1}+I_{22} F+\ldots+I_{2 m} F_{m}+\varepsilon_{2} \\
& Z_{P}=I_{p 1} F_{1}+I_{p 2} F_{1}+\ldots+I_{p m} F_{m}+\varepsilon_{p}
\end{aligned}
$$

Em que: $Z_{i}$ correspondem as i-ésimas variáveis originais padronizadas, com $\mathrm{i}=1,2, \ldots$, p; $F j$ referem-se aos fatores comuns, que respondem pelas correlaçóes existentes entre as variáveis e precisam ser identificados, onde $\mathrm{j}=1,2, \ldots, \mathrm{m}, I_{i j}$ dizem respeito as cargas fatoriais, que correspondem ao nível de relação linear entre $Z_{i}, F_{j}$ e mensuram a relevância dos fatores 
na formação de cada variável (correlação); e $\varepsilon_{i}$ representam os erros aleatórios que expressam os erros de medida e à variaçáo de $Z_{i}$, em que os fatores comuns incorporados no modelo não explicam.

Hair et al. (2005) destacam que a comunalidade, que se trata da proporção da variância de $X_{i}$ explicada pelo fator comum, pode ser obtida, de modo básico, pelo quadrado da carga fatorial. Já o escore fatorial é obtido por meio da multiplicaçáo dos coeficientes pelo valor das variáveis originais. Quando houver dois ou mais fatores, o escore fatorial corresponderá às coordenadas da variável em relação aos eixos ou fatores.

Segundo Fávero et al. (2009), o modelo apresentado assume as seguintes premissas: Interdependência dos fatores comuns, bem como suas respectivas distribuiçóes igualitárias, em que a média é zero e a variância um, com $\mathrm{k}-1, \ldots \mathrm{m}$; Interdependência dos fatores específicos com respectivas distribuiçóes igualitárias, com média zero e a variância $\psi_{i}$, sendo $i=1, \ldots, p$; e Interdependência de $F_{k}$ e $\varepsilon_{i}$.

A adequabilidade da técnica de análise fatorial é verificada por meio do uso de dois testes: esfericidade de Bartlett e a estatística Kaiser-Meyer-Olkin $(K M O)$. No teste de esfericidade de Bartlett, verifica-se a hipótese de que a matriz de correlação é uma matriz identidade com determinante unitário. A partir desse teste, pode-se concluir que, caso a matriz de correlaçáo seja igual à matriz identidade, a técnica de análise fatorial não deve ser utilizada, já que nessa situação as variáveis não estão correlacionadas (FÁVERO et al., 2009).

Quanto à estatística Kaiser-Meyer-Olkin $(K M O)$, os valores podem variar de zero a um, sendo que valores muito próximos de zero implicam em uma análise fatorial inadequada, haja vista a fraca correlaçâo entre as variáveis. Em contrapartida, quanto mais próximo da unidade, maior será a aceitabilidade do método. Ademais, se o valor do teste for superior a 0,6, tem-se a adequabilidade da utilização da análise fatorial (FÁVERO et al. 2009).

Procurando facilitar a interpretação dos dados, realizou-se a rotaçấo dos fatores. Segundo Loesch e Hoeltgebaum (2012), para realização deste procedimento, podem ser utilizados os critérios Varimax, Quartimax e Promax, porém o critério mais utilizado tratase da rotação ortogonal Varimax, uma vez que permite a maximização da variância dos quadrados dos fatores sobre a totalidade de variáveis. Esse critério é adotado neste estudo.

Após a rotação ortogonal da estrutura fatorial original, são estimados os escores fatoriais para cada elemento amostral, os quais são adotados na elaboração do Índice de Desempenho da provisão dos serviços de Saneamento Básico (IDSB) no Ceará. De acordo com Santana (2007), o índice dessa natureza pode ser expresso pela combinação linear dos escores fatoriais, obtidos pela análise fatorial, com a proporção da variância explicada pelos fatores individuais em relação à variância comum. Em termos algébricos, o IDSB pode ser representado pela equação (4):

$$
I D S B-\sum_{j=1}^{k}\left(\frac{\lambda_{j}}{\sum_{j=1}^{k} \lambda_{j}} F P_{j i}\right)
$$


Em que: $I D S B$ representa o índice de desempenho da provisão dos serviços de saneamento básico no Ceará; $\lambda_{j}$, percentual da variância explicada pelo fator $j ; k$, total de fatores escolhidos; $F P_{j i}$, escore fatorial, padronizado pelo elemento da amostra $i$, do fator $j$, que, pode ser expressado pela equação (5):

$$
F P_{j i}-\frac{F_{j}-F_{\min }}{F_{\max }-F_{\min }}
$$

Em que $F_{\text {min }}$ diz respeito ao escore fatorial mínimo do fator $j$; e $F_{\max }$, corresponde ao escore fatorial máximo do fator $j$.

A mensuração desse índice fornece um número, que pode variar de zero a um. Para tornar mais fácil a análise dos resultados, considera-se que, se o valor do IDSB for igual ou maior do que 0,70 , tem-se um elevado desempenho; se obtiver valor compreendido entre 0,35 e 0,69, desempenho intermediário; e se o valor do IDSB for menor do que 0,35, baixo desempenho da provisão dos serviços de saneamento básico no Ceará.

Como objetiva-se comparar o desempenho da provisão dos serviços de saneamento básico no estado do Ceará antes e após a implementação da Lei Nacional de Saneamento Básico (LNSB), instituída em 2007, então, a análise fatorial é realizada por meio de uma agregação dos dados para as variáveis em dois anos considerados, sendo um, imediatamente antes da implementação desta lei (2006) e outro depois dessa LNSB, mais precisamente, o último ano com dados disponíveis (2015), seguindo o procedimento sugerido por Souza et al. (2009). Na concepção desses autores, se a análise fatorial fosse adotada para cada ano individualmente, os fatores encontrados em um ano não seriam similares aos dos outros anos, não permitindo a comparação. Portanto, a análise considerou a matriz $\mathrm{M}$ de dimensão $312 \times 14$, em que: $M=\left[\begin{array}{l}M_{1} \\ M_{2}\end{array}\right]$, onde $M_{1}$ e $M_{2}$ referem-se às matrizes de ordem 156 x 7 correspondentes aos anos de 2006 e 2015, respectivamente, constituídas pelos valores das sete variáveis definidas na próxima seção em cada um dos 156 municípios cearenses considerados neste estudo com dados disponíveis para ao menos uma das variáveis utilizadas, em pelo menos um dos anos contemplados. Devido à indisponibilidade de informaçóes, 28

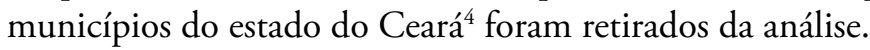

A justificativa para a ausência de dados por parte dos municípios listados pode estar relacionada ao fato de que, segundo Scriptore e Toneto Júnior (2012), os prestadores de serviços de saneamento básico fornecem informações ao Sistema Nacional de Informaçóes sobre Saneamento (SNIS) de maneira voluntária. Desse modo, municípios que expóem resultados satisfatórios nos índices de atendimento sanitário tem comprometimento na divulgação das informaçóes. Ademais, o banco de dados conta com deficiências, dentre as quais, podem ser destacadas o desconhecimento dos questionamentos e problemas no preenchimento não observado pelos testes de consistência empregados pelo SNIS.

4 Os municípios de Aiuaba, Ararendá, Banabuiú, Brejo Santo, Catarina, Deputado Irapuã Pinheiro, Granja, Ibaretama, Ipaporanga, Ipu, Ipueiras, Iracema, Jaguaribara, Jardim, Jucás, Madalena, Milhă, Nova Russas, Pedra Branca, Pindoretama, Poranga, Quixelô, Salitre, Santa Quitéria, São Luís do Curu, Solonópole, Tejuçuoca e Umirim não foram considerados neste estudo. 


\subsection{Variáveis consideradas e fonte dos dados}

A escolha das variáveis tomou como base os indicadores sugeridos no estudo desenvolvido por Scriptore e Toneto Júnior (2012) e Pereira et al. (2015) e foi coletada nos dados do Sistema Nacional de Informaçóes sobre Saneamento (SNIS) de 2006 e 2015 (último ano disponível), sendo definidas da seguinte forma:

a) Índice de atendimento urbano de água: Constituído pela razão entre a população urbana atendida com abastecimento de água e a população urbana residente nos municípios que possuem abastecimento de água;

b) Índice de perdas de distribuição: Diz respeito à razão dada pela diferença entre o volume de água produzido e consumido e o próprio volume produzido;

c) Índice de faturamento de água: Obtido a partir da relação entre o volume de água faturado e o somatório do volume de água produzido, tratada importada e tratada exportada;

d) Índice de consumo de água: Refere-se à razão do volume de água consumido e o somatório do volume de água produzido, de água tratada importada e volume de serviço;

e) Tarifa média praticada: Representada pela relação entre as receitas operacionais diretas de água e esgoto e o volume total de água faturado;

f) Despesa total de serviços: Elaborada por meio da relação entre as despesas totais de serviços e o volume total de água faturado;

g) Empregados próprios por 1000 ligaçóes de água e de esgoto: Formulada pela razão entre o total de empregados próprios e o total de ligaçóes ativas de água e de esgoto.

\section{ANÁLISE DOS RESULTADOS}

Essa seção estrutura-se em três partes, em que, na primeira, são mostradas as estatísticas descritivas das variáveis consideradas no estudo, na segunda, apresentam-se os resultados referentes à análise fatorial e, na terceira, são expostos os resultados do Índice de Desempenho da provisão de serviços de Saneamento Básico para os municípios pertencentes ao estado do Ceará.

\subsection{Estatísticas descritivas das variáveis consideradas}

Antes de apresentar os resultados acerca da análise fatorial e do Índice de Desempenho na provisão de serviços de Saneamento Básico, faz-se importante mostrar o comportamento estatístico das variáveis consideradas no estudo. Para tanto, a Tabela 1 apresenta as principais estatísticas descritivas das variáveis analisadas.

Os dados revelam que os índices de atendimento urbano de água, de consumo de água, despesa total de serviços e empregados próprios por 1000 ligaçóes de água e esgoto, apresentaram informaçóes mais dispersas em torno da média em 2006 do que em 2015. Neste último ano analisado, a heterogeneidade mais expressiva foi encontrada na relação de 
empregados próprios por 1000 ligações de água e esgoto, ao passo que a menor variabilidade ocorreu com a tarifa média praticada.

Tabela 1 - Estatísticas descritivas das variáveis utilizadas na análise fatorial

\begin{tabular}{l|c|c|c|c|c|c|c|c}
\hline \multirow{2}{*}{ Variáveis } & \multicolumn{2}{|c|}{ Mínimo } & \multicolumn{2}{c|}{ Máximo } & \multicolumn{2}{c|}{ Média } & \multicolumn{2}{c}{$\begin{array}{c}\text { Coeficiente de } \\
\text { variaçấo (\%) }\end{array}$} \\
\cline { 2 - 10 } & 2006 & 2015 & 2006 & 2015 & 2006 & 2015 & 2006 & 2015 \\
\hline $\begin{array}{l}\text { Índice de atendimento } \\
\text { urbano de água }\end{array}$ & 0,00 & 18,00 & 100,00 & 100,00 & 79,84 & 76,35 & 23,41 & 19,71 \\
\hline $\begin{array}{l}\text { Índice de perdas de } \\
\text { distribuição }\end{array}$ & $-0,09$ & 0,00 & 0,73 & 0,61 & 0,34 & 0,29 & 44,58 & 49,97 \\
\hline $\begin{array}{l}\text { Índice de faturamento } \\
\text { de água }\end{array}$ & 35,96 & 40,64 & 114,24 & 154,73 & 77,51 & 96,43 & 22,08 & 23,14 \\
\hline $\begin{array}{l}\text { Índice de consumo de } \\
\text { água }\end{array}$ & 31,54 & 39,29 & 114,24 & 100,01 & 69,46 & 71,12 & 22,04 & 20,46 \\
\hline $\begin{array}{l}\text { Tarifa média praticada } \\
\left(^{*}\right)\end{array}$ & 0,00 & 553,68 & 1913,53 & 3399,80 & 1139,57 & 2015,93 & 18,16 & 18,40 \\
\hline $\begin{array}{l}\text { Despesa total de } \\
\text { serviços }\left(^{*}\right)\end{array}$ & 210,14 & 738,53 & 6287,82 & 13231,54 & 1141,33 & 3562,70 & 55,62 & 50,23 \\
\hline $\begin{array}{l}\text { Empregados próprios } \\
\text { por 1000 ligaçóes de } \\
\text { água e de esgoto }\end{array}$ & 0,00 & 0,00 & 0,01 & 0,01 & 0,001 & 0,001 & 112,73 & 77,75 \\
\hline
\end{tabular}

Fonte: Elaboração própria com base nos dados da pesquisa.

$\left(^{*}\right)$ Expressas em reais.

Como se observa, em termos médios, o índice de atendimento urbano de água era melhor em 2006 do que em 2015, sendo que, dos 156 municípios analisados, 28 deles obtiveram o máximo índice no abastecimento urbano de água em 2006, enquanto, em 2015, apenas Amontada, Camocim, Jaguaribe e Tarrafas, situados, respectivamente, nas mesorregióes Norte, Noroeste, Jaguaribe e Centro Sul, apresentaram um nível máximo na razão da população urbana atendida com abastecimento de água pela população dos municípios com abastecimento de água na zona urbana.

Com relação ao índice de perdas na distribuição, em 2006, o município que apresentou o menor índice foi Chorozinho, localizado ao Norte do Estado, sendo o único que registrou um volume de água consumido maior que o produzido, justificando o resultado. Por outro lado, Tururu, também pertencente à mesorregiáo Norte cearense, destacou-se por apresentar a maior perda na distribuição de água no referido ano. Em 2015, Canindé (Norte cearense), Chorozinho (Norte cearense), São Benedito (Noroeste cearense) e Senador Sá (Noroeste cearense) não obtiveram tais perdas. Por outro lado, Maracanaú (Região Metropolitana de Fortaleza) registrou o pior percentual no referido índice. Ressaltase que, entre os períodos considerados, a perda estadual média na distribuição diminuiu, passando de 33,6 (2006) para 29,1 (2015), refletindo em uma melhoria no desempenho na provisão de serviços de saneamento básico.

No que concerne ao índice de faturamento de água, nota-se que, entre 2006 e 2015 , o faturamento de água aumentou em torno de 18,92, com destaque para os municípios 
de São Luis do Curu, ao Norte cearense, e Icó, no Centro Sul, com os piores índices, respectivamente, e Chorozinho, na Mesorregião Norte cearense, e Uruoca, ao Noroeste do Estado, com os maiores faturamentos.

Quanto ao consumo de água, verificou-se que, em média, os municípios cearenses tiveram um leve aumento de aproximadamente 1,67 nesse índice, entre os anos considerados. A tarifa média praticada variou de 0,00, em Meruoca, no Noroeste cearense, a 1.913,53, em Horizonte, na Região Metropolitana de Fortaleza, em 2006, e de 553,68 em Icapuí, na mesorregião de Jaguaribe, a 3.399,80, em Itaitinga, situado na Mesorregião Metropolitana de Fortaleza.

No tocante às despesas totais com serviços, observou-se que, em 2006, houve uma variação de 210,14 para Chorozinho (Norte cearense) a 6.287,821 para Pacujá (Noroeste cearense). Já em 2015, as despesas totais médias com serviços aumentaram em cerca de 2.421,37 em relação a 2006, sendo que Camocim, localizado ao Noroeste do Estado, teve a despesa mais baixa $(738,53)$, em detrimento do município de Itatira, situado ao Norte, com a maior despesa $(13.231,54)$. Ademais, em termos médios, a relação do total de empregados próprios por 1.000 ligaçóes ativas de água e esgoto foi menor em 2006 (0,0008) do que em $2015(0,0011)$.

\subsection{Análise fatorial}

$\mathrm{O}$ método de análise fatorial requer, a princípio, que se verifique se tal método é adequado aos dados considerados. Nesse sentido, o teste estatístico de esfericidade de Bartlett expressou significância a $1 \%$ de probabilidade, com valor de 1.468,205 e o teste de Kaiser-Meyer-Olkin (KMO), com valor de 0,639, comprovou que os dados são apropriados ao modelo aplicado.

Dada à adequabilidade deste instrumento analítico, aplicou-se a análise fatorial por meio do método dos componentes principais. Entretanto, salienta-se que, considerando sua versão original, uma determinada variável pode estar relacionada a mais de um fator, dificultando a interpretação. Desse modo, para superar tal problema, empregou-se a rotação ortogonal pelo método Varimax para garantir que cada variável esteja associada a apenas um fator. As raízes características da matriz de correlações que ultrapassam a unidade e seus respectivos percentuais de variância total explicada são expostas na Tabela 2. Esses fatores, que contemplam os indicadores de desempenho na provisão de serviços de saneamento básico, têm capacidade de explicar $80,08 \%$ da totalidade da variância dos dados, com destaque para a variância explicada pelo fator 1, que foi de $37,22 \%$. 
Tabela 2 - Raízes características da matriz de correlações simples (312x7) para a provisão de serviços de saneamento básico nos municípios cearenses, 2006 e 2015

\begin{tabular}{c|c|c|c}
\hline Fatores & Raiz Característica & Variância explicada pelo fator (\%) & Variância acumulada (\%) \\
\hline 1 & 2,61 & 37,22 & 37,22 \\
\hline 2 & 1,75 & 24,99 & 62,21 \\
\hline 3 & 1,25 & 17,88 & 80,08 \\
\hline
\end{tabular}

Fonte: Elaboração própria com base nos dados da pesquisa.

As cargas fatoriais rotacionadas e as comunalidades para os fatores em análise são mostradas na Tabela 3. Neste estudo, as cargas fatoriais que apresentaram valores absolutos superiores a 0,7 foram destacadas em negrito para indicar as variáveis que possuem relaçóes mais fortes com os diferentes fatores. Os valores das comunalidades explicitam que todas as variáveis obtiveram variabilidade captada pelos três fatores, de modo que as variáveis com os piores percentuais de explicação foram V1 e V7, com 0,591 e 0,733, respectivamente.

Tabela 3 - Cargas fatoriais após rotação ortogonal e comunalidades para os indicadores de desempenho na provisão de saneamento básico dos municípios cearenses, 2006 e 2015

\begin{tabular}{l|c|c|c|c}
\hline \multirow{2}{*}{ Variáveis } & \multicolumn{3}{c|}{ Cargas fatoriais } & \multirow{2}{*}{ Comunalidades } \\
\cline { 2 - 4 } & $\mathrm{F} 1$ & $\mathrm{~F} 2$ & $\mathrm{~F} 3$ & \\
\hline V1 - Índice de atendimento urbano de água & 0,02 & $-0,27$ & $\mathbf{0 , 7 2}$ & 0,59 \\
\hline V2 - Índice de perdas de distribuição & $\mathbf{- 0 , 9 7}$ & 0,01 & $-0,08$ & 0,96 \\
\hline V3 - Índice de faturamento de água & $\mathbf{0 , 8 4}$ & 0,35 & $-0,08$ & 0,83 \\
\hline V4 - Índice de consumo de água & $\mathbf{0 , 9 7}$ & $-0,09$ & 0,07 & 0,96 \\
\hline V5 - Tarifa média praticada & 0,02 & $\mathbf{0 , 8 9}$ & $-0,05$ & 0,79 \\
\hline V6 - Despesa total de serviços & 0,08 & $\mathbf{0 , 8 6}$ & $-0,05$ & 0,76 \\
\hline $\begin{array}{l}\text { V7 - Empregados próprios por 1000 ligaçóes de } \\
\text { água e esgoto }\end{array}$ & 0,03 & 0,14 & 0,84 & 0,73 \\
\hline
\end{tabular}

Fonte: Elaboração própria com base nos dados da pesquisa.

Como pode ser observado, o fator 1 tem forte correlação positiva com as variáveis V3 (Índice de faturamento de água) e V4 (Índice de consumo de água) e forte correlação negativa com a variável V2 (Índice de perdas na distribuição), pois à medida que se reduz as perdas na distribuição, aumenta o desempenho na provisão de serviços de saneamento básico. Segundo Cambrainha e Fontana (2015), apesar de o Brasil possuir disponibilidade hídrica, há uma forte intensificação dos problemas de saneamento básico no país, de modo que os recursos hídricos não são distribuídos de forma satisfatória, o que se agrava na região Nordeste, por conta do clima semiárido, que faz com que a região passe por longos períodos de estiagem e presencie racionamentos hídricos com frequência. Portanto, tais variáveis que compóem esse fator configuram os indicadores operacionais de água, estando consistente com o estudo de Scriptore e Toneto Júnior (2012). Assim, se um dado município cearense tiver escore positivo e elevado para esse fator, significa que está apresentando um nível 
satisfatório no que concerne aos indicadores que refletem a operacionalização no processo de distribuição de água.

$\mathrm{O}$ fator 2 correlaciona-se, positivamente, com as variáveis V5 e V6, que correspondem à tarifa média praticada e despesa total com serviços. Pode-se inferir que esse fator representa o indicador econômico e administrativo, seguindo a nomeação estabelecida por Scriptore e Toneto Júnior (2012). Desse modo, constata-se que maiores tarifas médias praticadas e despesas totais com serviços, melhoram o referido indicador, o que proporciona maior desempenho na provisão de serviços de saneamento básico.

As variáveis V1 (Índice de atendimento urbano de água) e V7 (Empregados próprios por 1000 ligaçóes de água e esgoto) estão fortemente correlacionados positivamente ao fator 3 e formam o indicador que pode ser chamado de abastecimento de água. Nesse sentido, quanto maior o abastecimento de água nos municípios cearenses, melhor o desempenho na provisão de serviços de saneamento básico, o que justifica os sinais positivos dos coeficientes. A variável V1 que faz parte deste fator está incluída no indicador de qualidade de abastecimento de água no estudo desenvolvido por Pereira et al. (2015).

\section{3 Índice de desempenho dos municípios cearenses na provisão de serviços de saneamento básico}

De acordo com o Gráfico 1, verifica-se que, considerando a classificação apresentada na metodologia, em 2006, 52,56\% dos municípios cearenses apresentaram índice intermediário no que concerne ao desempenho da provisão de serviços de saneamento básico no Estado. Nenhum município cearense apresentou nível elevado de desempenho, enquanto 74 municípios, que correspondem a 47,44\% do total de municípios analisados, obtiveram desempenhos considerados baixos. $\mathrm{O}$ índice de desempenho médio dos serviços de saneamento básico providos nos municípios cearenses foi de 0,35, considerado baixo. O município de Tururu, com 0,12 , foi o que apresentou o pior desempenho, enquanto o município de Amontada foi o que expressou melhor indicador (0,64).

Gráfico 1 - Distribuição relativa do Índice de Desempenho da Provisão dos Serviços de Saneamento Básico para os municípios cearenses, 2006 e 2015

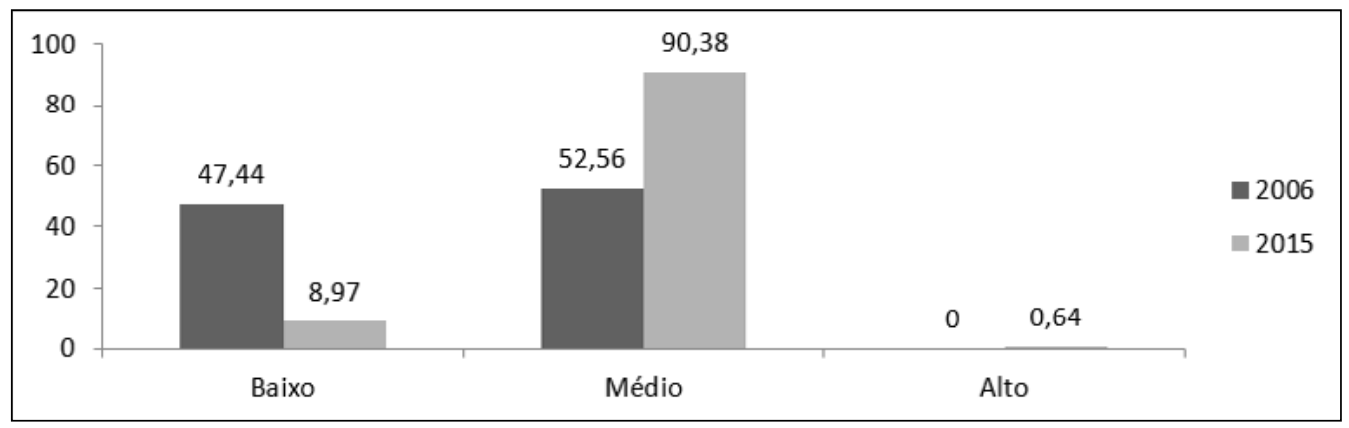

Fonte: Elaboração própria com base nos dados da pesquisa. 
Em 2015, conforme se observa no Gráfico 1, o número de municípios com níveis intermediários de desempenho passaram para 141, e o município de Viçosa do Ceará aparece como o único com elevado nível de desempenho. Por outro lado, os municípios de Acarapé, Aracoiaba, Maracanaú, Uburetama, Caucaia, Mauriti, Chaval, Horizonte, Santana do Cariri, Senador Pompeu, Pires Ferreira, Cedro, Barbalha e Juazeiro do Norte obtiveram baixos resultados no IDSB, representando $8,97 \%$ do total de municípios analisados, percentual menor do que em 2006, quando 47,44\% dos municípios tinham reduzidos níveis de desempenho no setor de saneamento.

Portanto, pode-se inferir que houve uma melhoria no desempenho da provisão de serviços de saneamento básico nos municípios cearenses ao se comparar os resultados de 2006 com 2015. Essa melhoria propicia benefícios sociais e econômicos, conforme destacado por Hutton e Haller (2004) e Caruso et al. (2014). Apesar desse avanço alcançado, percebe-se que ainda há municípios analisados que permaneceram com baixo desempenho da provisão dos serviços de saneamento básico após a vigência da Lei Nacional de Saneamento Básico, sinalizando que há carências que precisam ser abordadas. De acordo com Heller (2007), a eliminação de tais deficiências requer a adoção de um novo marco institucional orientado para a universalização dos serviços, com base no princípio da equidade e o reconhecimento das assimetrias existentes na prestação de serviços.

\section{CONSIDERAÇÓES FINAIS}

A provisão dos serviços de saneamento básico no Brasil tem enfrentado dificuldades, especialmente no que tange ao abastecimento de água e ao esgotamento sanitário, que problematizam a saúde pública e o meio ambiente. A Lei Nacional de Saneamento Básico, instituída em 2007, surge como um instrumento que visa a melhoria nos indicadores de desempenho nesse segmento. Nesse sentido, buscando examinar se houve melhorias no desempenho da provisão de serviços de saneamento básico nos municípios cearenses, o estudo teve como intento, mensurar um índice de provisão dos serviços de saneamento básico nos municípios cearenses e comparar tal desempenho em um período anterior (2006) à instauração da referida lei e o último período com dados disponíveis (2015).

Os resultados da análise fatorial demonstraram que foram extraídos três fatores de desempenho do saneamento básico para representar o conjunto de variáveis explicativas consideradas neste estudo. O fator F1 foi nomeado como a dimensão referente aos indicadores operacionais de água e respondeu por cerca de $37,22 \%$ da variância total. A dimensão relacionada ao indicador econômico e administrativo, indicada pelo fator F2, explicou $24,99 \%$ da variância total, e o fator 3, representado pelo indicador de abastecimento de água, obteve uma variância total explicada de aproximadamente 17,88\%.

Apesar de ter predominado o nível intermediário de desempenho na provisão de serviços de saneamento básico nos dois anos analisados, os resultados mostraram que houve uma melhoria nesse índice após a vigência da Lei Nacional de Saneamento Básico, já que aproximadamente $39 \%$ dos municípios estudados saíram do nível baixo para intermediário de desempenho, entre os períodos considerados. Ademais, nenhum município registrou alto IDSB antes da LNSB e, após a vigência da lei, Viçosa do Ceará passa a apresentar essa classificação. 
Os resultados possibilitam inferir que ocorrem grandes dispersóes nos municípios cearenses quando analisado o nível de desempenho na provisão dos serviços de saneamento básico, fato que demonstra a necessidade de novos estudos que visem verificar a razão dessa heterogeneidade a fim de homogeneizar o referido desempenho, com o intuito de os municípios apresentarem desempenhos mais satisfatórios.

\section{REFERÊNCIAS}

ANTHONJ, C.; RECHENBURG, A.; KISTEMANN, T. Water, sanitation and hygiene in wetlands. A case study from the Ewaso Narok Swamp, Kenya. International Journal of Hygiene and Environmental Health, v. 219, n. 7, p. 606-616, 2016.

CAGECE - COMPANHIA DE ÁGUA E ESGOTO DO CEARÁ. Índice de Coberturas Disponível em: <https://www.cagece.com.br/numeros/indice-de-cobertura $>$. Acesso em: 26/07/2017.

CAMBRAINHA, G. M. G.; FONTANA, M. E. Análise da aplicação de investimentos em perdas de água no nordeste brasileiro. Electronic Journal of Management, Education and Environmental Technology (REGET), v. 19, n. 2, p. 983-994, 2015.

CARDOSO, E. R.; MELO, A. S. S. A.; DALFOVO, W. C. T. Municipalização plena dos serviços de saneamento básico em Mato Grosso: efeitos e condiçóes de desempenho. In: Encontro Nacional de Economia, 43, 2015. Anais... Florianópolis, SC: ANPEC, 2015.

CARUSO, B. A.; FREEMAN, M. C.; GAM, J. V.; DREIBELBIS, R.; SABOORI, S.; MUGA, R.; RHEIGANS, R. Assessing the impact of a school-based latrine cleaning and handwashing program on pupil absence in Nyanza Province, Kenya: a cluster-randomized trial. Tropical Medicine \& International Health, v. 19, n. 10, p. 1185-1197, 2014.

CARVALHO, A. C.; LIMA, P. V. P. S.; SOUSA, R. P. A gestão municipal do saneamento básico no Estado do Ceará. In: Congresso da Sociedade Brasileira de Economia, Administração e Sociologia Rural Nordeste, 8, 2013. Anais... Parnaíba, PI: SOBER Nordeste, 2013.

CUNHA, A. S. Saneamento básico no Brasil: desenho institucional e desafios federativos. Texto para Discussáo 1565. Rio de Janeiro: IPEA, 2011.

DIÁRIO DO NORDESTE. CE abaixo do Nordeste em saneamento básico. Jornal Diário do Nordeste. Fortaleza, CE, junho de 2011.

DINIZ, M. F. A. Governança da água: uma avaliação dos serviços brasileiros de abastecimento de água e esgotamento sanitário nos anos de 2002, 2007 e 2012.

Dissertaçáo de Mestrado em Economia. Natal, RN: Universidade Federal do Rio Grande do Norte, 75p., 2016. 
FÁVERO, L. P. et al. Análise de dados: modelagem multivariada para tomada de decisóes. Rio de Janeiro: Elsevier, 2009.

FERREIRA, H.; CASSIOLATO, M.; GONZALEZ, R. Uma experiência de desenvolvimento metodológico para avaliação de programas: o modelo lógico do programa segundo tempo. Texto para Discussáo n. 1369. Brasília, IPEA, 2009.

FRACAROLLI, G. S. O uso de indicadores no planejamento das políticas públicas no Brasil. São Paulo, FGV, 2015. Disponível em: <http://bibliotecadigital.fgv.br/dspace/ handle/10438/14163>. Acesso em 28/07/2017.

GALVÃO JÚNIOR, A. C. Regulação e universalizaçáo dos serviços de água e esgoto: estudo do Nordeste brasileiro. São Paulo: USP, 2008. 202 f. Tese (Saúde Pública) Universidade de São Paulo, 2008.

GALVÃO JUNIOR, A. C.; PAGANINI, W. S. Aspectos conceituais da regulação dos serviços de água e esgoto no Brasil. Engenharia Sanitária e Ambiental, v.14, n.1, p. 7988, 2009.

GARFI, M.; FERRER-MARTÍ, L. Decision-making criteria and indicators for water and sanitation projects in developing countries. Water Science and Technology, v. 64, n. 1, p. 83-101, 2011.

HAIR JR, J. F.; ANDERSON, R. E.; TATHAM, R. L.; BLACK, W. C. Análise Multivariada de Dados. 5. ed. Porto Alegre: Bookman, 2005. 593p

HELLER, L. Basic Sanitation in Brazil: lessons from the past, opportunities from the present, challenges for the future. Journal of Comparative Social Welfare, v. 23, n. 2, p. $141-153,2007$.

HUTTON, G.; HALLER, L.; WATER, S. Evaluation of the costs and benefits of water and sanitation improvements at the global level. World Health Organization. 2004. Disponível em: < http://apps.who.int/iris/handle/10665/68568>. Acesso em: 25/03/2018.

KEMPER, K.; SADOFF, C. The global water challenge. World Bank Global Issues Seminar Series. Disponível em: < http://siteresources.worldbank.org/EXTABOUTUS/ Resources/WaterPaper.pdf>. Acesso em: 25/03/2018.

LOESCH, C.; HOELTGEBAUM, M. Métodos estatísticos multivariados. São Paulo: Editora Saraiva, 2012.

IPECE - Instituto de Pesquisa e Estratégia Econômica do Ceará. Ceará em Números 2011. Disponível em: < http://www2.ipece.ce.gov.br/publicacoes/ceara_em_ numeros/2011/completa/index.htm>. Acesso em: 25/07/2017. 
INSTITUTO TRATA BRASIL. Ceará fica entre 10 piores sistemas de saneamento do Brasil. 2016. Disponível em: <http://www.tratabrasil.org.br/ceara-fica-entre-10-pioressistemas-de-saneamento-do-brasil>. Acesso em: 26/07/2017.

MINGOTI, S. A. Análise de dados através de métodos de Estatística Multivariada Uma abordagem aplicada. Belo Horizonte: Editora UFMG, 2005.

MOREIRA, T. Saneamento básico: desafios e oportunidades. Revista do BNDES, Rio de Janeiro, v. 3, n. 6, p.1-18, 1996.

NOVAES, R. C.; JACOBI, P. R. Comitês de bacia, capital social e eficiência institucional: reflexóes preliminares sobre influências recíprocas. In: Encontro da Associação Nacional de Pós Graduação e Pesquisa em Ambiente e Sociedade, 1, 2002. Anais... Indaiatuba, SP: ANPPAS, 2002.

NASCIMENTO, J. A. S. Manejo de águas pluviais. Atlas de Saneamento 2011. Rio de Janeiro: Diretoria de Geociências do IBGE, 2011. Disponível em: <http://biblioteca.ibge. gov.br/visualizacao/livros/liv53096_cap10.pdf>. Acesso em: 27/07/2017.

ORTIZ-CORREA, J. S.; RESENDE FILHO, M.; DINAR, A. Impact of access to water and sanitation services on educational attainment. Water Resources and Economics, v. 14, p. 31-43, 2016.

PEREIRA, M. T.; SILVA, F. F.; GIMENES, M. L.; ZANATTA, O. A. Desenvolvimento de Indicador de Qualidade de Saneamento Básico Urbano (IQSBU) e aplicação em cidades paranaenses. Revista em Agronegócio e Meio Ambiente. Maringá, PR, v. 8, n. 1, p. 135-164, 2015.

PIMENTEL; GOMES. Curso de Estatística Experimental. Piracicaba - SP: ESALQ/ USP, 1985.

ROSEMARIN, A.; EKANE, N.; CALDWELL, I.; KVARNSTROM, E.; MCCONVILLE, J.; RUBEN, C.; FOGDE, M. Pathways for Sustainable Sanitation. IWA Publishing, 2008.

SANTANA, A. C. Índice de desempenho competitivo das empresas de polpa de frutas do Estado do Pará. Revista de Economia e Sociologia Rural. Rio de Janeiro, v.45, n.3, p.749-775, 2007.

SCHWEMLEIN, S.; CRONK, R.; BARTRAM, J. Indicators for Monitoring Water, Sanitation, and Hygiene: a systematic review of indicator selection methods.

International Journal of Environmental Research and Public Health, v. 13, n. 3, 333, 2016. 
SCRIPTORE, J. S.; TONETO JÚNIOR, R. A estrutura de provisão dos serviços de saneamento básico no Brasil: uma análise comparativa do desempenho dos provedores públicos e privados. Revista de Administraçáo Pública. Rio de Janeiro, v.46, n.6, p.14791504, 2012.

SILVA, V. H. M. C. Determinantes do acesso aos serviços de saneamento básico no Ceará: o caso do esgotamento sanitário. TEXTO PARA DISCUSSÁO IPECE, n. 64. FortalezaCE 2009.

SOUZA, P. M.; PONCIANO, N. J., MATA, H. T. C.; BRITO, M. N.; GOLINSKI, J. Padrão de desenvolvimento tecnológico dos municípios das Regiōes Norte e Noroeste do Rio de Janeiro. Revista de Economia e Sociologia Rural. Piracicaba, SP, v. 47, n.4, p. 945-969, 2009.

VENSON, A. H.; RODRIGUES, K. C. T. T.; CAMARA, M. R. G. Distribuição espacial do acesso aos serviços de saneamento básico nas microrregióes brasileiras de 2006 a 2013. In: Encontro da Associação Brasileira de Estudos Regionais e Urbanos, 13, 2015. Anais... Curitiba, PR: ENABER, 2015.

VILANOVA NETA, M. A. Manejo de resíduos sólidos. Atlas de Saneamento 2011. Rio de Janeiro: Diretoria de Geociências do IBGE, 2011. Disponível em: <http://biblioteca. ibge.gov.br/visualizacao/livros/liv53096_cap9.pdf>. Acesso em: 27/07/2017.

WORLD HEALTH ORGANIZATION; UNICEF. Progress on drinking water, sanitation and hygiene: 2017 update and SDG baselines. World Health Organization, 2017. Disponível em: <https://www.unicef.org/publications/index_96611.html>. Acesso em 25/03/ 2018. 